\title{
Cerebral glucose metabolic prediction from amnestic mild cognitive impairment to Alzheimer's dementia: a meta-analysis
}

\author{
Hai Rong Ma', Li Qin Sheng ${ }^{1}$, Ping Lei Pan², Gen Di Wang ${ }^{2}$, Rong Luo², Hai Cun Shi², Zhen Yu Dai ${ }^{3 *}$ \\ and Jian Guo Zhong ${ }^{2^{*}}$
}

\begin{abstract}
Brain ${ }^{18}$ F-fluorodeoxyglucose positron emission tomography (FDG-PET) has been utilized to monitor disease conversion from amnestic mild cognitive impairment (aMCl) to Alzheimer's dementia (AD). However, the conversion patterns of FDG-PET metabolism across studies are not conclusive. We conducted a voxel-wise meta-analysis using Seed-based $d$ Mapping that included 10 baseline voxel-wise FDG-PET comparisons between $93 \mathrm{aMCl}$ converters and $129 \mathrm{aMCl}$ nonconverters from nine longitudinal studies. The most robust and reliable metabolic alterations that predicted conversion from $\mathrm{aMCl}$ to $\mathrm{AD}$ were localized in the left posterior cingulate cortex (PCC)/precuneus. Furthermore, meta-regression analyses indicated that baseline mean age and severity of cognitive impairment, and follow-up duration were significant moderators for metabolic alterations in $\mathrm{AMCl}$ converters. Our study revealed hypometabolism in the left PCC/precuneus as an early feature in the development of AD. This finding has important implications in understanding the neural substrates for $\mathrm{AD}$ conversion and could serve as a potential imaging biomarker for early detection of $\mathrm{AD}$ as well as for tracking disease progression at the predementia stage.
\end{abstract}

Keywords: Alzheimer's dementia, Mild cognitive impairment, FDG-PET, Conversion, Meta-analysis, Seed-based d mapping

\section{Background}

Alzheimer's dementia (AD), an age-related neurodegenerative disorder, is the most common type of dementia worldwide, placing heavy burdens on global economic and social development [1-3]. Mild cognitive impairment (MCI), especially in its amnestic form, is considered a prodromal state of $\mathrm{AD}$ as it is associated with an annual conversion rate to AD of $10-15 \%$ [4]. However, a substantial proportion of patients with MCI will not progress to $\mathrm{AD}$ or other types of dementia, and may even remain stable or revert to normal cognition [5]. Individuals with amnestic MCI (aMCI) identified during prodromal phases as being at risk for conversion to $\mathrm{AD}$ may benefit most from early

\footnotetext{
*Correspondence: daiycsy@sina.com; yc3yjgzhong@163.com

${ }^{3}$ Department of Radiology, School of Medicine, Affiliated Yancheng Hospital, Southeast University, West Xindu Road 2\#, Yancheng, Jiangsu Province 224001, People's Republic of China

${ }^{2}$ Department of Neurology, School of Medicine, Affiliated Yancheng Hospital, Southeast University, West Xindu Road 2\#, Yancheng, Jiangsu Province 224001, People's Republic of China

Full list of author information is available at the end of the article
}

interventions. Unfortunately, it is difficult to differentiate aMCI converters from non-converters using clinical and neuropsychological assessments.

In contrast to brain amyloid-beta positron emission tomography (PET) that has no place in the routine work-up of suspected AD [6], brain ${ }^{18}$ F-fluorodeoxyglucose (FDG) PET is now a well-established tool in detecting and defining the distribution of neural injury or synaptic dysfunction in $\mathrm{AD}$ and MCI/aMCI [7-9]. Cerebral hypometabolism assessed with FDG-PET in AD patients was frequently observed in the posterior cingulate cortex (PCC), precuneus, and parietotemporal association areas $[7,10]$. A similar distribution has also been identified in patients with $\mathrm{MCI} / \mathrm{aMCI}$, whereas the magnitude and spatial extent of hypometabolism is less than that observed in patients with $\mathrm{AD}[10,11]$. Many longitudinal studies have utilized FDG-PET to aid in predicting the conversion from $\mathrm{aMCI}$ to $\mathrm{AD}[12,13]$. However, the cerebral regions where early FDG-PET changes occur are not always concordant across studies. For example, when comparing aMCI converters to non- 
converters, glucose hypometabolism has been identified in a wide range of brain regions, including in the temporoparietal association areas [14-18], PCC [17-20], precuneus [21], medial and lateral temporal lobes [16, 18, 20, 22], medial and lateral frontal cortices (including the anterior cingulate cortex [ACC]) $[17,19,20,23]$. Given the variability, Schroeter et al. preliminarily conducted a meta-analysis of voxel-based neuroimaging studies using anatomical likelihood estimation (ALE) and found that the left inferior parietal lobe and right precuneus were the most consistent regions that could predict the conversion from $\mathrm{MCI}$ to $\mathrm{AD}$ [24]. However, their results should be interpreted with caution as they were derived from the integration of studies using FDG-PET, single photon emission computed tomography (SPECT), and structural magnetic resonance imaging (MRI) modalities [24]. In addition, no FDG-PET studies after 2007 were included [14, 21], with several more FDGPET studies on larger samples having been conducted since then $[16,17,19,20,22,23]$. Furthermore, quantitative voxel-based meta-analytic methods have improved in recent years, allowing for a more accurate analysis [25-27]. Therefore, further investigation is necessary to verify the finding by Schroeter et al. that changes in the left inferior parietal lobe and right precuneus can predict the conversion from MCI to AD [24].

The aim of this work was to carry out a modified meta-analysis in order to identify brain regions of FDGPET metabolic alterations that could be used to predict the conversion from aMCI to AD. In order to do this, we pooled voxel-based FDG-PET studies to determine the most consistent and reliable brain regions that showed alterations in glucose metabolism. The metaanalysis was conducted using Seed-based $d$ Mapping (SDM), a popular meta-analytical technique [26, 28-31] that has been well-validated and employed to analyze voxel-based neuroimaging studies to explore the robustness of brain activity or structural changes in many neuropsychiatric disorders [27, 32-36].

\section{Methods}

\section{Literature search and study selection}

Electronic searches were conducted in the PubMed, Web of Science, and Embase databases using a combination of keywords ("Mild cognitive impairment" OR "Alzheimer's disease") AND (("Positron Emission Tomography" OR "PET") AND ("Fluorodeoxyglucose" OR "FDG")) OR "FDG-PET") on February 17, 2017. No publication language or date restrictions were used for the electronic searches. The reference lists of relevant original studies, systematic reviews, and meta-analyses were manually screened for additional qualified publications as well. Criteria for considering studies for this meta-analysis were as follows: (1) studies were published as original research articles in peer-reviewed journals; (2) studies were longitudinal that followed patients diagnosed with aMCI (single domain or multiple domains) [37-41] to determine which of them converted to AD; (3) studies conducted a direct voxel-based statistical comparison of baseline FDGPET metabolic differences between patients with aMCI who converted to $\mathrm{AD}$ (aMCI converters) and those that did not (aMCI non-converters); (4) studies reported peak Montreal Neurological Institute (MNI) or Talairach/Tournoux coordinates; (5) significant results of regional FDGPET metabolic differences were reported within one study using a consistent statistical threshold. In cases with multiple studies and overlapping patient groups that reported similar neuroimaging findings, the study with the largest sample size was included. Exclusion criteria were as follows: (1) studies enrolled subjects with aMCI that subsequently converted to other dementia types during the follow-up or enrolled patients with non-aMCI at baseline; (2) studies did not report peak coordinates or they were not obtained after contacting the corresponding author; (3) studies limited their analyses to ROI approaches only. Recorded data were extracted from each included study, including the first author's name, year of publication, mean age, gender, and sample size of aMCI converters and non-converters, cognitive impairment severity (mean Mini-Mental State Examination (MMSE) score), education level, follow-up duration, diagnostic criteria, and imaging characteristics (e.g., post-processing software, smoothing kernel, and statistical threshold). In addition, peak coordinates and their effect sizes (e.g., t-values) of regional FDG-PET metabolic differences between aMCI converters and non-converters were extracted for the following voxel-wise meta-analysis. The literature search and selection, and data extraction were independently performed by two investigators (H.R.M. and L.Q.S). Any discrepancies were discussed with another investigator (J. G.Z.) until they were resolved by consensus. This work was conducted in accordance with the guidelines set by the Meta-analysis Of Observational Studies in Epidemiology (MOOSE) [42].

\section{Data analysis \\ Main voxel-wise meta-analysis}

Regional glucose metabolism differences between aMCI converters and aMCI non-converters were meta-analyzed in a voxel-wise manner using the SDM software package (latest version 5.141, available at https://www.sdmproject. $\mathrm{com} /$ ). The SDM approach has been described in detail in other publications [26, 28-30] and the tutorial is available for review (http://www.sdmproject.com/software/tutorial. pdf). Briefly, an effect-size signed map and an effect-size variance map from the peak coordinates and their effect sizes of regional glucose metabolic differences between aMCI converters and aMCI non-converters was first separately recreated for each individual FDG-PET study using 
an anisotropic via a $20 \mathrm{~mm}$ full-width at half maximum (FWHM) un-normalized Gaussian kernel. It should be noted that this kernel is designed to assign indicators of proximity to report coordinates but not to smooth any image, which is different in nature from the smoothing kernel. Moreover, this kernel has been found to have excellent control over false positives. Following this, a mean map was created by calculating the random-effects mean of the study maps in a voxel-wise manner, which was weighted by sample size and intra-study variability, and additional between-study heterogeneity. Statistical significance was determined using a default threshold ( $p=0.005$, peak height $Z=1$, cluster extent $=10$ voxels), which optimized the balance of false positives and negatives $[26,28]$.

\section{Sensitivity analyses}

In order to assess the replicability of the results, a wholebrain voxel-based jackknife sensitivity analysis was performed by iteratively repeating the same statistical analysis, removing one study at a time [28, 29]. Jackknife analyses were thresholded with the default settings $(p=0$. 005 , peak height $Z=1$, cluster extent $=10$ voxels) $[26,28]$.

\section{Heterogeneity analysis}

A random-effects model with $\mathrm{Q}$ statistics (a chi-square distribution converted to $\mathrm{z}$ values) was utilized to examine the between-study heterogeneity of individual clusters. A permutation approach $(\mathrm{p}=0.005$, peak height $\mathrm{z}=$ 1 , cluster extent $=10$ voxels) was used to determine statistical significance [43].

\section{Publication bias analysis}

Possible publication biases in the main meta-analytic peaks were examined by analyzing the funnel plots and Egger's tests [44]. Significance was determined as an asymmetry of funnel plots and a $p$-value less than 0.05 on Egger's test.

\section{Meta-regression analysis}

Meta-regression analyses were conducted to explore the confounding effects of baseline mean age and severity of cognitive impairment (mean MMSE score), and followup duration that could potentially influence the metaanalytic results. Statistical significance was thresholded at a more conservative p-value of 0.0005 and a cluster extent of 10 voxels in accordance with previous metaanalyses $[28,30]$.

\section{Results}

\section{Included studies}

Our initial search yielded a total of 3886 titles reviewed for inclusion. After a careful screen of the literatures according to the inclusion and exclusion criteria, nine original studies that reported 10 comparisons [14-16, 19-23, 45] were finally eligible for the meta-analysis (Fig. 1), which included
93 patients classified as aMCI converters (mean age range 57.8-77.7 years and mean MMSE scores range 19.9-27.8) and 129 patients classified as aMCI non-converters (mean age range 60-75.8 years and mean MMSE scores range 23. 9-28.3). The mean follow-up durations ranged from 12 to 60 months. Details of demographic, clinical and imaging characteristics of the included studies are summarized in Table 1.

\section{Main voxel-wise meta-analysis}

As shown in Fig. 2 and Table 2, the main voxel-wise meta-analysis identified significant regional hypometabolism in the left/right PCC/precuneus (BAs 23, 7, and 30) , left/right ACC (BAs 11, 32, 24, and 10), left middle temporal gyrus (BAs 21, 20, and 38), left middle temporal gyrus (BAs 21 and 37), and left middle frontal gyrus, orbital part (BA 11) in aMCI converters relative to aMCI non-converters at baseline.

\section{Sensitivity analyses}

The jackknife sensitivity analyses revealed that regional hypometabolism in the left/right PCC/precuneus (BAs 23, 7 , and 30) was the most reliable alteration as it was replicable in all 10 comparisons. Regions of hypometabolism in the left/right ACC (BAs 11, 32, 24, and 10) and left middle temporal gyrus (BAs 21, 20, and 38) were replicable in all but one comparison combinations. Regions of hypometabolism in the left middle temporal gyrus (BAs 21 and 37) and left middle frontal gyrus, orbital part (BA 11) failed to emerge in two of the comparison combinations. These results are summarized in Table 3.

\section{Heterogeneity analysis}

As demonstrated in Additional file 1: Figure S1 and Table 4, significant between-study heterogeneity was identified in the right $\mathrm{PCC} /$ precuneus (BA 23), right superior temporal gyrus (BAs 22 and 21), left middle frontal gyrus (BA 46), left/right ACC (BAs 11, 32, 24, and 25), left middle frontal gyrus, orbital part (BA 11), and left middle temporal gyrus (BAs 21 and 20).

\section{Publication bias analysis}

No significant publication biases were detected in the regions obtained from the main voxel-wise meta-analysis as revealed by the relative symmetry of the funnel plots (Additional file 2: Figure S2) and statistically nonsignificant Egger's tests (Table 2).

\section{Meta-regression analysis}

A meta-regression analysis revealed that aMCIconverters with an older mean age at baseline (available from all 10 comparisons) exhibited more regional hypometabolism in the left middle temporal gyrus (BAs 21, 20 , and 37) and less regional hypometabolism in the left 


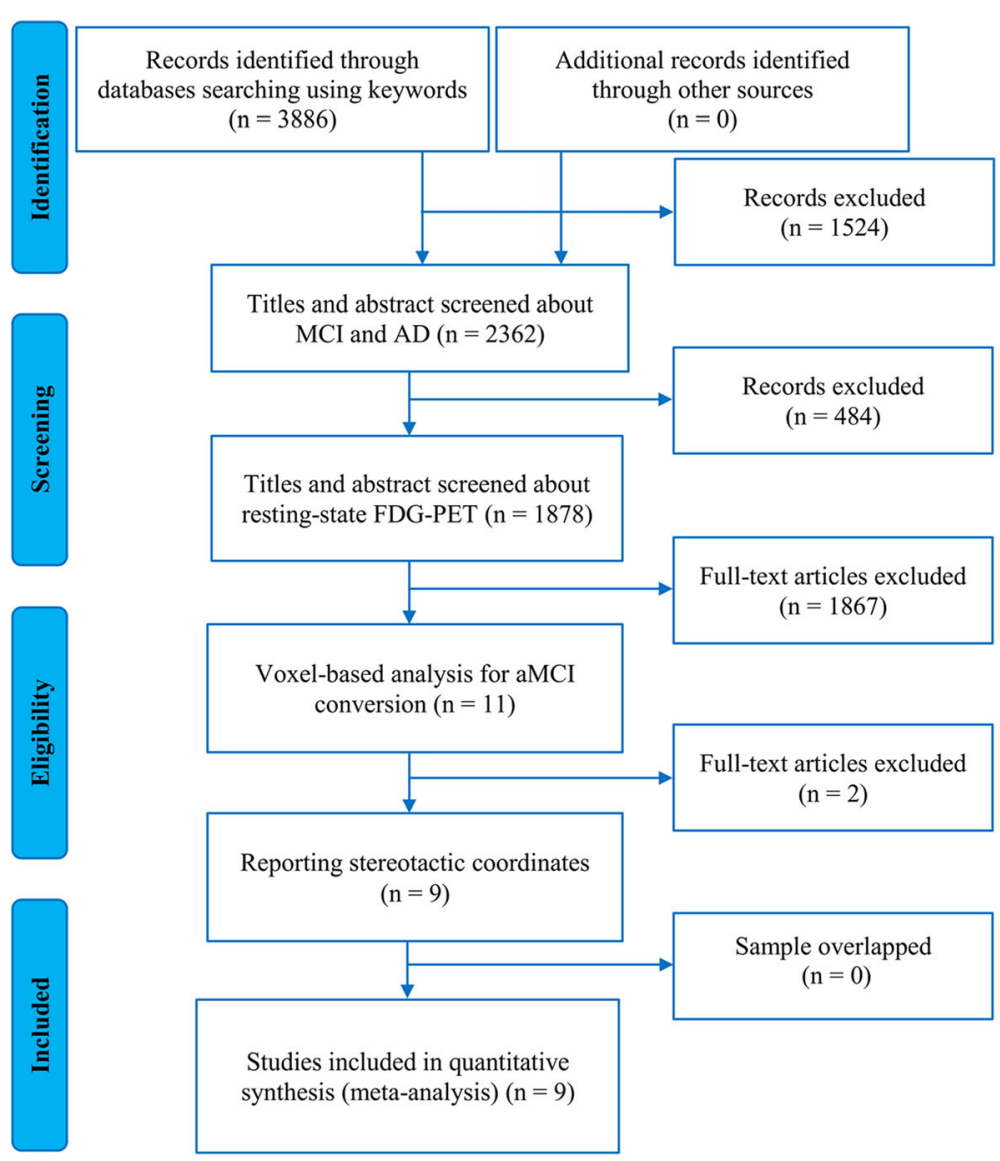

Fig. 1 Flow chart for the literature search. Abbreviations: MCl, mild cognitive impairment; AD, Alzheimer's dementia; FDG-PET, ${ }^{18}$ F-fluorodesoxyglucose positron emission tomography; aMCl, amnestic $\mathrm{MCl}$

superior/middle frontal gyri, orbital part (BA 11). Lower mean MMSE scores of aMCI converters at baseline (available from all 10 comparisons) were associated with more regional hypometabolism in the left middle frontal gyrus (BA 9) and left temporal pole (BAs 28 and 36). In addition, findings of the meta-regression analysis suggested that a longer mean follow-up duration in aMCIconverters (available from all 10 studies) was associated with more regional hypometabolism in the left middle frontal gyrus (BAs 46 and 9). The results of these metaregression analyses are summarized in Table 5 .

\section{Discussion}

To the best of our knowledge, this was the first voxelwise meta-analysis that only pooled FDG-PET studies to determine the most robust brain regions with glucose metabolism alterations in prediction conversion from $\mathrm{aMCI}$ to $\mathrm{AD}$. In addition to the main voxel-wise metaanalysis in this study, several complementary analyses, such as jackknife sensitivity, heterogeneity, and publication bias analyses were conducted to test the robustness of our results. Pooling these findings, we observed that regional hypometabolism in the left $\mathrm{PCC} /$ precuneus at baseline was the most reliable and robust difference between aMCI converters and aMCI non-converters. Moreover, meta-regression analyses revealed that regional hypometabolism in the left $\mathrm{PCC} /$ precuneus in aMCI converters relative to aMCI non-converters at baseline was not biased by potential confounding variables, such as mean age and severity of global cognitive impairment at baseline, or follow-up durations across studies, which lend further support for the robustness of this finding.

The PCC and its adjacent precuneus, situated in the posteromedial part of the parietal cortex, make intensive connections with the medial temporal lobe (MTL) and other cerebral areas [46-48]. The PCC/precuneus are believed to play a pivotal role in the default mode network (DMN), which shows the highest level of baseline activity at rest and is deactivated during tasks in healthy subjects [49-51]. Impairments in the DMN, one of the most investigated intrinsic networks in patients with $\mathrm{AD}$ and aMCI, contribute to characteristic cognitive deficits, such as episodic memory and visuospatial processes [17, 46, 48, 52-55]. Compelling evidence from functional and metabolic 
Table 1 Characteristics of FDG-PET studies included in the meta-analysis

\begin{tabular}{|c|c|c|c|c|c|c|c|c|c|c|}
\hline Study & Sample size (fem & & Age (SD) & $\begin{array}{l}\text { Education } \\
\text { (years) }\end{array}$ & $\begin{array}{l}\text { MMSE } \\
\text { (SD) }\end{array}$ & Software & FWHM & Threshold & $\begin{array}{l}\text { Follow-up } \\
\text { Duration }\end{array}$ & $\begin{array}{l}\text { Diagnostic } \\
\text { Criteria }\end{array}$ \\
\hline \multirow{2}{*}{$\begin{array}{l}\text { Chetelat et al., } \\
2003 \text { [14] }\end{array}$} & Converters & $7(4)$ & $73(5.1)$ & NA & $26.3(1)$ & \multirow[t]{2}{*}{ SPM99 } & \multirow[t]{2}{*}{ NA } & \multirow{2}{*}{$\begin{array}{l}0.05 \\
\text { corrected }\end{array}$} & \multirow[t]{2}{*}{18 months } & \multirow{2}{*}{$\begin{array}{l}\text { Petersen et al. } \\
\text { (2001) [37] }\end{array}$} \\
\hline & Non-converters & $10(5)$ & $67.8(7)$ & NA & $27.8(1.2)$ & & & & & \\
\hline \multirow{2}{*}{$\begin{array}{l}\text { Drzezga et al., } \\
2003 \text { [21] }\end{array}$} & Converters & $8(3)$ & 71.6 (4.3) & NA & $27.9(1.2)$ & \multirow[t]{2}{*}{ SPM99 } & \multirow[t]{2}{*}{$12 \mathrm{~mm}$} & \multirow{2}{*}{$\begin{array}{l}0.001 \\
\text { uncorrected }\end{array}$} & \multirow[t]{2}{*}{12 months } & \multirow{2}{*}{$\begin{array}{l}\text { Petersen et al. } \\
\text { (1999) [38] }\end{array}$} \\
\hline & Non-converters & $12(7)$ & $68.6(6.5)$ & NA & $28.1(1.3)$ & & & & & \\
\hline \multirow{2}{*}{$\begin{array}{l}\text { Mosconi et al., } \\
2004 \text { [15] }\end{array}$} & Converters & $8(N A)$ & $71(5)$ & $8(3)$ & $26.7(1.3)$ & \multirow[t]{2}{*}{ SPM99 } & \multirow[t]{2}{*}{$12 \mathrm{~mm}$} & \multirow{2}{*}{$\begin{array}{l}0.05 \\
\text { corrected }\end{array}$} & 12.0 months & \multirow{2}{*}{$\begin{array}{l}\text { Petersen et al. } \\
\text { (2001) [37] }\end{array}$} \\
\hline & Non-converters & $29(N A)$ & $66(8)$ & $10(5)$ & $28.3(1.4)$ & & & & 12.1 months & \\
\hline \multirow{2}{*}{$\begin{array}{l}\text { Salmon et al., } \\
2008 \text { [19] }\end{array}$} & Converters & $17(12)$ & $71.3(5.9)$ & $10.8(2.5)$ & $24.0(2.2)$ & \multirow[t]{2}{*}{ SPM2 } & \multirow[t]{2}{*}{$12 \mathrm{~mm}$} & \multirow{2}{*}{$\begin{array}{l}\text { 0.005, } \\
\text { uncorrected }\end{array}$} & \multirow[t]{2}{*}{36 months } & \multirow{2}{*}{$\begin{array}{l}\text { Petersen et al. } \\
\text { (2001) [37] } \\
\text { and Winblad } \\
\text { et al. (2004) } \\
\text { [39] }\end{array}$} \\
\hline & Non-converters & $17(7)$ & $66.2(7.0)$ & $12.3(5.2)$ & $25.7(1.9)$ & & & & & \\
\hline \multirow{2}{*}{$\begin{array}{l}\text { Fouquet et al., } \\
2009 \text { [23] }\end{array}$} & Converters & $7(5)$ & $73.3(4.3)$ & $11.0(4.7)$ & $26.7(1.0)$ & \multirow[t]{2}{*}{ SPM2 } & \multirow[t]{2}{*}{$10 \mathrm{~mm}$} & \multirow{2}{*}{$\begin{array}{l}0.005 \\
\text { uncorrected }\end{array}$} & 17.5 months & \multirow{2}{*}{$\begin{array}{l}\text { Petersen et al. } \\
\text { (2001) [37] }\end{array}$} \\
\hline & Non-converters & $10(6)$ & $\begin{array}{l}70.4 \\
(11.2)\end{array}$ & $9.9(3.6)$ & $28.1(1.0)$ & & & & 18.2 months & \\
\hline \multirow[t]{2}{*}{$\begin{array}{l}\text { Kim et al., } \\
2010 \text { [20] }\end{array}$} & Converters $^{\mathrm{a}}$ & $7(\mathrm{NA})$ & $57.8(3.7)$ & NA & $\begin{array}{l}27.00 \\
(1.15)\end{array}$ & \multirow[t]{2}{*}{ SPM2 } & \multirow[t]{2}{*}{$12 \mathrm{~mm}$} & \multirow[t]{2}{*}{$\begin{array}{l}0.001 \\
\text { uncorrected }\end{array}$} & 60 months & \multirow[t]{2}{*}{$\begin{array}{l}\text { Petersen et al. } \\
\text { (1999) [38] }\end{array}$} \\
\hline & Non-converters ${ }^{a}$ & $5(N A)$ & $60.0(4.2)$ & NA & $\begin{array}{l}28.00 \\
(2.12)\end{array}$ & & & & & \\
\hline $\begin{array}{l}\text { Kim et al., } \\
2010 \text { [20] }\end{array}$ & Converters $^{\mathrm{b}}$ & $8(N A)$ & $71.7(4.4)$ & NA & $\begin{array}{l}27.50 \\
(1.87)\end{array}$ & SPM2 & $12 \mathrm{~mm}$ & $\begin{array}{l}0.001 \\
\text { uncorrected }\end{array}$ & 60 months & $\begin{array}{l}\text { Petersen et al. } \\
\text { (1999) [38] }\end{array}$ \\
\hline & Non-converters ${ }^{\mathrm{b}}$ & $6(N A)$ & $75.8(4.1)$ & NA & $\begin{array}{l}26.63 \\
(1.69)\end{array}$ & & & & & \\
\hline Morbelli et al., & Converters & $9(7)$ & 77.1 (5.9) & $8.6(4.3)$ & $27.8(0.9)$ & SPM2 & $10 \mathrm{~mm}$ & & 22.6 months & Petersen et al. \\
\hline & Non-converters & $11(5)$ & $74.0(5.3)$ & $8.7(4.5)$ & $27.8(1.4)$ & & & & 26.5 months & \\
\hline Pagani et al., & Converters & $10(8)$ & $77.7(4.8)$ & $8.8(3.9)$ & $27.5(1.4)$ & SPM2 & $8 \mathrm{~mm}$ & 0.05, & 22.0 months & Petersen et al. \\
\hline & Non-converters & $9(4)$ & $75.8(5.9)$ & $11.0(5.3)$ & $27.0(2.0)$ & & & & 23.7 months & \\
\hline Sohn et al., & Converters & $12(9)$ & 69.5 (7.7) & $7.5(2.9)$ & 19.9 (3.5) & SPM8 & $12 \mathrm{~mm}$ & 0.005 & 24 months & Albert et al. \\
\hline & Non-converters & $20(14)$ & $71.6(7.0)$ & $9.2(4.1)$ & $23.9(3.4)$ & & & & & \\
\hline
\end{tabular}

Abbreviations: FDG-PET ${ }^{18} \mathrm{~F}$-fluorodesoxyglucose positron emission tomography, SD standard deviation, MMSE Mini-Mental State Examination, FWHM full width at half maximum, NA not available, SPM statistical parametric mapping

a early-onset amnestic mild cognitive impairment

blate-onset amnestic mild cognitive impairment

studies suggests prominent involvement of the PCC/precuneus in $\mathrm{AD}[46,54,56]$. In healthy individuals, the PCC/ precuneus are characterized by higher rates of metabolism and cerebral blood flow than those of the global brain mean [57]. In humans, the PCC/precuneus develop phylogenetically and ontogenetically late, making them the last to become myelinated and the first to be affected by pathological processes [46]. Because of their thinner myelin sheaths as well as unique metabolism, connectivity, and vascular characteristics, the $\mathrm{PCC} /$ precuneus are preferably vulnerable for neurodegenerative processes, such as amyloid deposition, which are observed in the early stages of $\mathrm{AD}$ development [46, 57-59]. In terms of $\mathrm{AD}$ genesis, previous studies have focused on the MTL; however,

Table 2 Clusters of regional hypometabolism in aMCl converters relative to aMCI non-converters

\begin{tabular}{|c|c|c|c|c|c|}
\hline Anatomical label & Peak MNI coordinate $(x, y, z)$ & Number of voxels & SDM-Z value & $\begin{array}{l}p \text { value } \\
\text { (SDM) }\end{array}$ & $p$ value (Egger's test) \\
\hline Left/Right PCC/precuneus (BAs 23, 7, and 30) & $-4,-48,28$ & 1959 & -2.73 & $\sim 0$ & 0.37 \\
\hline Left/Right ACC (BAs 11, 32, 24, and 10) & $-4,32,0$ & 668 & -1.72 & 0.00047 & 0.23 \\
\hline Left middle temporal gyrus (BAs 21, 20, and 38) & $-44,4,-26$ & 501 & -1.66 & 0.00067 & 0.16 \\
\hline Left middle temporal gyrus (BAs 21 and 37) & $-58,-52,-2$ & 185 & -1.65 & 0.00074 & 0.13 \\
\hline Left middle frontal gyrus, orbital part (BA 11) & $-20,40,-18$ & 22 & -1.39 & 0.0031 & 0.30 \\
\hline
\end{tabular}

Abbreviations: $M C l$ amnestic mild cognitive impairment, $M N I$ Montreal Neurological Institute, SDM Seed-based $d$ Mapping, $P C C$ posterior cingulate cortex, ACC anterior cingulate cortex, $B A$ Brodmann area 


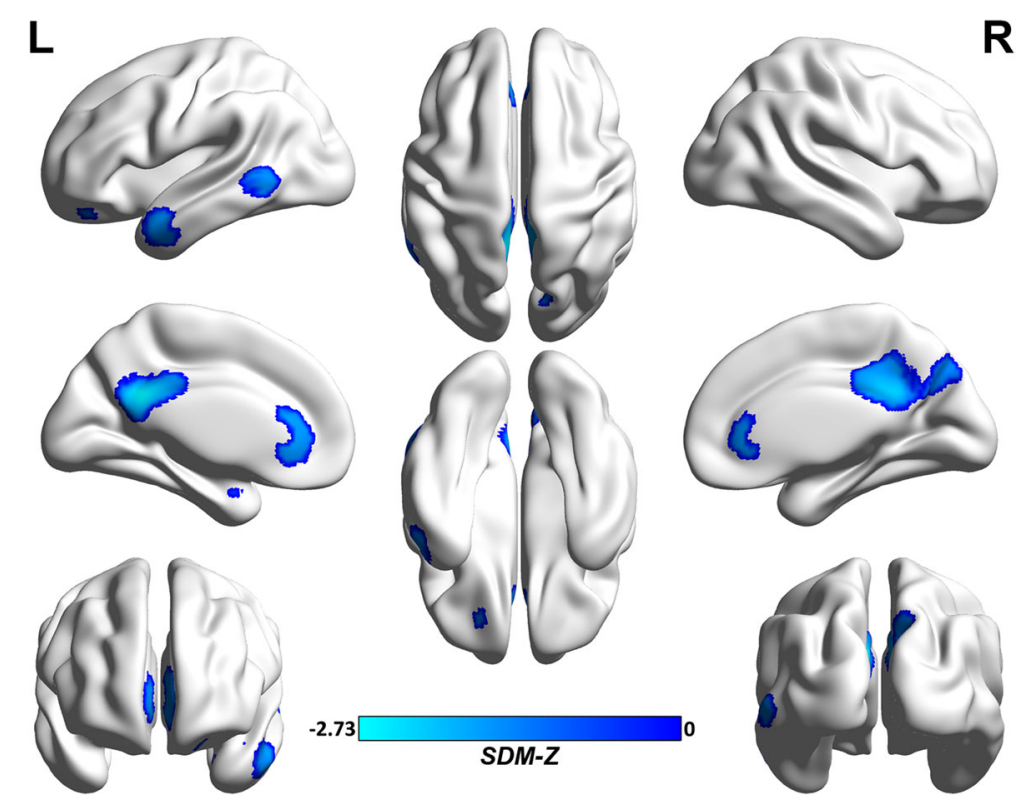

Fig. 2 Brain hypometabolism map for the main voxel-wise meta-analysis in aMCl converters and aMCl non-converters. Abbreviations: aMCl, amnestic mild cognitive impairment; L, left; R, right; SDM, Seed-based $d$ Mapping. The color bar indicates the maximum and the minimum SDM-Z values

increasing attention has shifted to the PCC/precuneus because of their key role in disrupting memory during initial AD development [46]. Compared to structural MRI and cerebrospinal fluid (CSF) tau biomarkers, FDG-PET abnormalities in the PCC/precuneus provide the strongest, earliest (preceding cognitive impairments) indication of individuals who will later progress to AD [58]. Our metaanalysis supports this evidence and consistently identified regional hypometabolism at baseline in the $\mathrm{PCC} /$ precuneus as an effective predictor of $\mathrm{aMCI}$ to $\mathrm{AD}$ conversion. Progressive dysfunction of the $\mathrm{PCC} /$ precuneus might lead to impaired neural connectivity and vice versa, revealing the neurodegenerative process that ultimately results in cognitive dysfunction and clinical symptoms. Thus, regional hypometabolism in the $\mathrm{PCC} /$ precuneus appears to be an imaging marker that can be used to characterize $\mathrm{AD}$ development.

Interestingly, in terms of consistency of prediction, we observed an asymmetric pattern of regional hypometabolism. Although in the main voxel-wise meta-analysis, the right $\mathrm{PCC} /$ precuneus was identified, these regions were associated with significant between-study heterogeneity. Including more eligible studies in future investigations may increase our statistical power. The underlying neurobiology of the asymmetric involvement remains unclear; however, increasing evidence indicates greater susceptibility of the left hemisphere to degeneration than the right. Moreover, it has been suggested that brain structures located in the left hemisphere are affected earlier and more severely in AD [60-65].
Indeed, greater metabolic dysfunction has been reported in the left hemisphere when compared to that of the right in patients with $\mathrm{AD}$ [61]. Further, a meta-analysis of voxel-based morphometry studies conducted by Ferreira and colleagues found that atrophy of the left MTL was the most robust brain structural biomarker in predicting conversion from aMCI to AD [66]. The PCC/ precuneus have intimate functional and structural connections with the MTL, which collaborate the accordance of lateralized alterations described by Ferreira et al. Moreover, previous studies have demonstrated dynamic alterations in the degree of left-right asymmetry during disease progression [63, 67-69]. Consequently, a left hemispheric predominance of regional hypometabolism and atrophy in these regions might be another early characteristic that could be used to track disease progression.

The findings of the present meta-analysis were not consistent with those of a prior meta-analysis that combined three different imaging modalities (PET, SPECT, and structural MRI) [24]. That meta-analysis identified the left inferior parietal lobe and right precuneus as the brain regions most predictive in differentiating $\mathrm{MCI}$ converters from non-converters [24]. This discrepancy is not surprising and can be explained by the several factors. First, the results of the previous meta-analysis are hard to interpret and may be biased due to their use of several analytic approaches and modalities, which represent different neuropathophysiological information [24]. In contrast, the findings of our study are easier to 
Table 3 Jackknife sensitivity analysis

\begin{tabular}{|c|c|c|c|c|c|}
\hline All studies but ... & $\begin{array}{l}\text { Left/Right PCC/precuneus } \\
\text { (BAs 23, 7, and 30) }\end{array}$ & $\begin{array}{l}\text { Left/Right ACC } \\
\text { (BAs 11, 32, 24, and 10) }\end{array}$ & $\begin{array}{l}\text { Left middle temporal gyrus } \\
\text { (BAs 21, 20, and 38) }\end{array}$ & $\begin{array}{l}\text { Left middle temporal } \\
\text { gyrus (BAs } 21 \text { and 37) }\end{array}$ & $\begin{array}{l}\text { Left middle frontal gyrus, } \\
\text { orbital part (BA 11) }\end{array}$ \\
\hline $\begin{array}{l}\text { Chetelat et al., } \\
2003 \text { [14] }\end{array}$ & Yes & Yes & Yes & Yes & Yes \\
\hline $\begin{array}{l}\text { Drzezga et al., } \\
2003 \text { [21] }\end{array}$ & Yes & Yes & Yes & Yes & Yes \\
\hline $\begin{array}{l}\text { Mosconi et al., } \\
2004 \text { [15] }\end{array}$ & Yes & Yes & Yes & Yes & Yes \\
\hline $\begin{array}{l}\text { Salmon et al., } \\
2008 \text { [19] }\end{array}$ & Yes & No & Yes & No & No \\
\hline $\begin{array}{l}\text { Fouquet et al., } \\
2009 \text { [23] }\end{array}$ & Yes & Yes & Yes & Yes & Yes \\
\hline $\begin{array}{l}\text { Kim et al., } \\
2010^{a}[20]\end{array}$ & Yes & Yes & Yes & Yes & No \\
\hline $\begin{array}{l}\text { Kim et al., } \\
2010^{\mathrm{b}}[20]\end{array}$ & Yes & Yes & Yes & Yes & Yes \\
\hline $\begin{array}{l}\text { Morbelli et al., } \\
2010 \text { [22] }\end{array}$ & Yes & Yes & No & Yes & No \\
\hline $\begin{array}{l}\text { Pagani et al., } \\
2010 \text { [16] }\end{array}$ & Yes & Yes & Yes & No & Yes \\
\hline $\begin{array}{l}\text { Sohn et al., } \\
2015 \text { [45] }\end{array}$ & Yes & Yes & Yes & Yes & Yes \\
\hline Total & 10 out of 10 & 9 out of 10 & 9 out of 10 & 8 out of 10 & 8 out of 10 \\
\hline
\end{tabular}

Abbreviations: PCC posterior cingulate cortex, ACC anterior cingulate cortex, BA Brodmann area, Yes the region(s) reported, No the region(s) not reported a early-onset amnestic mild cognitive impairment

blate-onset amnestic mild cognitive impairment

interpret and understand as we only included FDG-PET studies that provide unique metabolic alterations. Second, we used a SDM approach in the current study, which is based on and modifies previous meta-analytic methods, (e.g., the ALE and multilevel kernel density analysis) [29, 70-72]. Specifically, the SDM introduces a series of improvements and novel features, allowing us to further conduct comprehensive complementary evaluations, including sensitivity, heterogeneity, publication bias, and meta-regression analyses, to test the robustness of our findings and to minimize the risk of false positive results [26, 28-30, 70-72]. Third, the current metaanalysis included eight more published datasets, which increased our statistical power. Together, these factors make the current results more accurate than the previously published meta-analysis.
In addition to the left PCC/precuneus identified in the main voxel-wise meta-analysis, several other brain regions exhibited hypometabolism, such as the right $\mathrm{PCC} /$ precuneus, bilateral $\mathrm{ACC}$, and left middle temporal and frontal gyri. However, the finding of altered glucose metabolism in these regions was not very reliable, as determined by additional complementary analyses of jackknife sensitivity, heterogeneity, publication bias, and metaregression. Several moderator variables were examined to understand the potential source of this heterogeneity. The meta-regression analyses indicated that mean age and severity of cognitive impairment at baseline as well as follow-up duration had significant effects on alterations in brain metabolism. Many other moderators, such as age at onset, disease duration, education level, aMCI subtype (amnestic single domain and multiple domains), genotype,

Table 4 Regions with heterogeneity

\begin{tabular}{|c|c|c|c|c|}
\hline Anatomical label & Peak MNI coordinate $(x, y, z)$ & Number of voxels & SDM-Z value & $p$ value \\
\hline Right PCC/precuneus (BA 23) & $12,-40,34$ & 374 & 1.49 & 0.00012 \\
\hline Right superior temporal gyrus (BAs 22 and 21) & $60,-28,6$ & 440 & 1.20 & 0.00037 \\
\hline Left middle frontal gyrus (BA 46) & $-28,40,30$ & 270 & 1.57 & 0.000084 \\
\hline Left/Right ACC (BAs 11, 32, 24, and 25) & $-4,36,4$ & 216 & 1.25 & 0.00030 \\
\hline Left middle frontal gyrus, orbital part (BA 11) & $-18,58,-14$ & 184 & 1.26 & 0.00029 \\
\hline Left middle temporal gyrus (BAs 21 and 20) & $-50,2,-28$ & 85 & 1.12 & 0.00056 \\
\hline
\end{tabular}


Table 5 Meta-regression analyses

\begin{tabular}{|c|c|c|c|c|c|}
\hline & Anatomical label & Peak MNI coordinate $(x, y, z)$ & Number of voxels & SDM-Z value & $p$ value \\
\hline \multirow[t]{4}{*}{ Effect of age } & \multicolumn{5}{|c|}{ Association of regional glucose metabolism effect size and older mean age of aMCl converters } \\
\hline & Left middle temporal gyrus (BAs 21 and 20) & $-54,4,-28$ & 152 & -1.64 & 0.00024 \\
\hline & Left middle temporal gyrus (BA 37) & $-56,-58,-2$ & 64 & -1.69 & 0.00016 \\
\hline & Left superior /middle frontal gyri, orbital part (BA 11) & $-18,58,-14$ & 53 & 1.73 & 0.000076 \\
\hline
\end{tabular}

Effect of illness Association of regional glucose metabolism effect size and lower mean MMSE scores of aMCI converters

severity

$\begin{array}{lllll}\text { Left middle frontal gyrus (BA 9) } & -24,22,42 & 21 & -2.74 & 0.00014 \\ \text { Left temporal pole (BAs 28 and 36) } & -20,8,-34 & 13 & -2.69 & 0.00017\end{array}$

Effect of follow-up Association of regional glucose metabolism effect size and longer mean follow-up duration duration

Left middle frontal gyrus (BAs 46 and 9)

$-30,40,30$

255

$-3.30$

0.000037

Abbreviations: SDM Seed-based $d$ Mapping, MNI Montreal Neurological Institute, $a M C l$ amnestic mild cognitive impairment, $P C C$ posterior cingulate cortex, $A C C$ anterior cingulate cortex, BA Brodmann area

and cerebrovascular risk factors might also affect brain metabolism. In addition, variations in imaging protocols and analytic procedures across studies may have influenced the observed heterogeneity. However, we were unable to address many of the described confounding factors as we were limited to performing analyses on data available from the included studies. Future studies with large, homogeneous samples and standardized protocols are warranted to control these moderator effects and to verify the results of our meta-analysis.

Although our comprehensively modified meta-analysis enabled us to successfully identify which brain regions might serve as predictive indicators of conversion from $\mathrm{aMCI}$ to $\mathrm{AD}$, the present study had several limitations. First, the SDM technique was based on reported peak coordinates and their effect sizes rather than raw imaging data. Although this is common practice in coordinate-based meta-analyses, the approach may produce less accurate results [26, 28-30, 70-72]. Future studies based on statistical parametric maps or raw imaging data would highly increase the power of our results $[73,74]$. Second, the exclusion of studies that did not report stereotaxic coordinates likely reduced our power to detect less-robust alterations, and may have biased our findings [75]. Third, the results identified in our meta-analysis were based on between-group FDGPET differences. Further investigations would benefit from utilizing these results as selected reference ROIs for discrimination on an individual basis. Fourth, the present meta-analysis only included FDG-PET studies. The use of FDG-PET, in combination with other imaging and CSF evaluation approaches, such as restingstate functional MRI, structural MRI, tau and perfusion imaging techniques, as well as CSF $\beta$-amyloid and tau level assessments, should be advocated as this integrated information would increase the power for early AD detection [58].

\section{Conclusions}

Using a modified meta-analytic approach, the present study demonstrates the most robust FDG-PET changes in the left PCC/precuneus in aMCI converters relative to aMCI non-converters at baseline. This finding has important implications in understanding the neural substrates for the prediction of conversion from aMCI to AD. Hypometabolism in the left PCC/precuneus was determined as an early feature in the development of $\mathrm{AD}$ and this might serve as a candidate imaging biomarker for early detection and for tracing disease progression. Further work is warranted to determine the potential of these findings in clinical use and their value in the development of future therapeutic interventions in individuals at the predementia stage of AD.

\section{Additional files}

Additional file 1 Figure S1. Regions of the heterogeneity map from the SDM heterogeneity analysis. Abbreviations: SDM, Seed-based d Mapping; L, left; $R$, right. The color bar indicates the maximum and the minimum SDM-Z values. (TIFF $684 \mathrm{~kb}$ )

Additional file 2 Figure S2. Funnel plots of the peak coordinates from the main meta-analysis for detecting publication bias. Abbreviations: MNI, Montreal Neurological Institute. (TIFF $184 \mathrm{~kb}$ )

\section{Abbreviations}

ACC: Anterior cingulate cortex; AD: Alzheimer's dementia; ALE: Anatomical likelihood estimation; aMCl: amnestic mild cognitive impairment;

BAs: Brodmann areas; FDG-PET: ${ }^{18}$ F-fluorodeoxyglucose positron emission tomography; FWHM: Full-width at half maximum; MMSE: Mini-mental state examination; MNI: Montreal Neurological Institute; MOOSE: Meta-analysis of observational studies in epidemiology; MRI: Magnetic resonance imaging; PCC: Posterior cingulate cortex; ROI: Regions of interest; SDM: Seed-based $d$ Mapping; SPECT: Single photon emission computed tomography

Acknowledgements

We thank all the authors of the included studies.

\section{Funding}

This work was supported by the National Natural Science Foundation of China (Grant No. 81601161). 


\section{Availability of data and materials}

The datasets supporting the conclusions of this article are included in the article and its additional files.

\section{Authors' contributions}

HRM and JGZ design the whole study. HRM, GDW, RL, HCS and QLS searched and selected the studies, analyzed the data, prepared figures and drafted the article. PLP undertook the statistical analysis. ZYD, PLP, HCS, HRM and JGZ participated in the interpretation of data. HRM and SLQ wrote the manuscript. JGZ and ZYD revised the manuscript. All authors read and approved the final manuscript.

\section{Ethics approval}

This article does not contain any studies with human participants performed by any of the authors.

\section{Competing interests}

The authors declare that they have no competing interests.

\section{Author details}

'Department of Neurology, Traditional Chinese Medicine Hospital of Kunshan, Kunshan, People's Republic of China. ${ }^{2}$ Department of Neurology, School of Medicine, Affiliated Yancheng Hospital, Southeast University, West Xindu Road 2\#, Yancheng, Jiangsu Province 224001, People's Republic of China. ${ }^{3}$ Department of Radiology, School of Medicine, Affiliated Yancheng Hospital, Southeast University, West Xindu Road 2\#, Yancheng, Jiangsu Province 224001, People's Republic of China.

\section{Received: 23 January 2018 Accepted: 3 April 2018}

Published online: 23 April 2018

\section{References}

1. Chan KY, Wang W, Wu JJ, Liu L, Theodoratou E, Car J, et al. Epidemiology of Alzheimer's disease and other forms of dementia in China, 1990-2010: a systematic review and analysis. Lancet. 2013:381:2016-23.

2. Goodman RA, Lochner KA, Thambisetty M, Wingo TS, Posner SF, Ling SM. Prevalence of dementia subtypes in U.S. Medicare fee-for-service beneficiaries, 2011-2013. Alzheimers Dement. 2017;13:28-37.

3. Scheltens P, Blennow K, Breteler MM, de Strooper B, Frisoni GB, Salloway S, et al. Alzheimer's disease. Lancet. 2016;388:505-17.

4. Petersen RC, Roberts RO, Knopman DS, Boeve BF, Geda YE, Ivnik RJ, et al. Mild cognitive impairment: ten years later. Arch Neurol. 2009;66:1447-55.

5. Pandya SY, Clem MA, Silva LM, Woon FL. Does mild cognitive impairment always lead to dementia? A review. J Neurol Sci. 2016:369:57-62.

6. Hoilund-Carlsen PF, Barrio JR, Gjedde A, Werner TJ, Alavi A. Circular inference in dementia diagnostics. J Alzheimers Dis. 2018;

7. Kato T, Inui Y, Nakamura A, Ito K. Brain fluorodeoxyglucose (FDG) PET in dementia. Ageing Res Rev. 2016;30:73-84.

8. Mosconi L. Brain glucose metabolism in the early and specific diagnosis of Alzheimer's disease. FDG-PET studies in MCl and AD. Eur J Nucl Med Mol Imaging. 2005;32:486-510.

9. Mosconi L, Tsui WH, Herholz K, Pupi A, Drzezga A, Lucignani G, et al. Multicenter standardized 18F-FDG PET diagnosis of mild cognitive impairment, Alzheimer's disease, and other dementias. J Nucl Med. 2008;49:390-8.

10. He W, Liu D, Radua J, Li G, Han B, Sun Z. Meta-analytic comparison between PIB-PET and FDG-PET results in Alzheimer's disease and MCI. Cell Biochem Biophys. 2015;71:17-26.

11. Langbaum JB, Chen K, Lee W, Reschke C, Bandy D, Fleisher AS, et al. Categorical and correlational analyses of baseline fluorodeoxyglucose positron emission tomography images from the Alzheimer's Disease Neuroimaging Initiative (ADNI). Neurolmage. 2009;45:1107-16.

12. Yuan Y, Gu ZX, Wei WS. Fluorodeoxyglucose-positron-emission tomography, single-photon emission tomography, and structural MR imaging for prediction of rapid conversion to Alzheimer disease in patients with mild cognitive impairment: a meta-analysis. Am J Neuroradiol. 2009;30:404-10.

13. Smailagic N, Vacante M, Hyde C, Martin S, Ukoumunne O, Sachpekidis C. (1)(8)F-FDG PET for the early diagnosis of Alzheimer's disease dementia and other dementias in people with mild cognitive impairment (MCI). Cochrane Database Syst Rev. 2015;1:Cd010632.
14. Chételat G, Desgranges B, De la Sayette V, Viader F, Eustache F, Baron JC. Mild cognitive impairment: can FDG-PET predict who is to rapidly convert to Alzheimer's disease? Neurology. 2003;60:1374-7.

15. Mosconi L, Perani D, Sorbi S, Herholz K, Nacmias B, Holthoff V, et al. MCl conversion to dementia and the APOE genotype: a prediction study with FDG-PET. Neurology. 2004;63:2332-40.

16. Pagani M, Dessi B, Morbelli S, Brugnolo A, Salmaso D, Piccini A, et al. MCl patients declining and not-declining at mid-term follow-up: FDG-PET findings. Curr Alzheimer Res. 2010;7:287-94.

17. Yi D, Choe YM, Byun MS, Sohn BK, Seo EH, Han J, et al. Differences in functional brain connectivity alterations associated with cerebral amyloid deposition in amnestic mild cognitive impairment. Front Aging Neurosci. 2015;7:15.

18. Teipel SJ, Kurth J, Krause B, Grothe MJ. The relative importance of imaging markers for the prediction of Alzheimer's disease dementia in mild cognitive impairment - beyond classical regression. Neuroimage Clin. 2015;8:583-93.

19. Salmon E, Lekeu F, Garraux G, Guillaume B, Magis D, Luxen A, et al. Metabolic correlates of clinical heterogeneity in questionable Alzheimer's disease. Neurobiol Aging. 2008;29:1823-9.

20. Kim SH, Seo SW, Yoon DS, Chin J, Lee BH, Cheong HK, et al. Comparison of neuropsychological and FDG-PET findings between early- versus late-onset mild cognitive impairment: a five-year longitudinal study. Dement Geriatr Cogn Disord. 2010;29:213-23.

21. Drzezga A, Lautenschlager N, Siebner H, Riemenschneider M, Willoch F, Minoshima S, et al. Cerebral metabolic changes accompanying conversion of mild cognitive impairment into Alzheimer's disease: a PET follow-up study. Eur J Nucl Med Mol Imaging. 2003;30:1104-13.

22. Morbelli S, Piccardo A, Villavecchia G, Dessi B, Brugnolo A, Piccini A, et al. Mapping brain morphological and functional conversion patterns in amnestic MCl: a voxel-based MRI and FDG-PET study. Eur J Nucl Med Mol Imaging. 2010;37:36-45.

23. Fouquet M, Desgranges B, Landeau B, Duchesnay E, Mezenge F, de la Sayette $V$, et al. Longitudinal brain metabolic changes from amnestic mild cognitive impairment to Alzheimer's disease. Brain. 2009;132:2058-67.

24. Schroeter ML, Stein T, Maslowski N, Neumann J. Neural correlates of Alzheimer's disease and mild cognitive impairment: a systematic and quantitative metaanalysis involving 1351 patients. Neurolmage. 2009:47:1196-206.

25. Eickhoff SB, Nichols TE, Laird AR, Hoffstaedter F, Amunts K, Fox PT, et al. Behavior, sensitivity, and power of activation likelihood estimation characterized by massive empirical simulation. Neurolmage. 2016;137:70-85.

26. Lim L, Radua J, Rubia K. Gray matter abnormalities in childhood maltreatment: a voxel-wise meta-analysis. Am J Psychiatry. 2014;171:854-63.

27. Norman $\sqcup$, Carlisi C, Lukito S, Hart H, Mataix-Cols D, Radua J, et al. Structural and functional brain abnormalities in attention-deficit/hyperactivity disorder and obsessive-compulsive disorder: a comparative meta-analysis. JAMA Psychiatry. 2016;73(8):815-25.

28. Radua J, Rubia K, Canales-Rodriguez EJ, Pomarol-Clotet E, Fusar-Poli P, Mataix-Cols D. Anisotropic kernels for coordinate-based meta-analyses of neuroimaging studies. Front Psychiatry. 2014;5:13.

29. Radua J, Mataix-Cols D. Voxel-wise meta-analysis of grey matter changes in obsessive-compulsive disorder. Br J Psychiatry. 2009;195:393-402.

30. Radua J, Mataix-Cols D, Phillips ML, El-Hage W, Kronhaus DM, Cardoner N, et al. A new meta-analytic method for neuroimaging studies that combines reported peak coordinates and statistical parametric maps. European Psychiatry. 2012;27:605-11.

31. Sheng L, Ma H, Zhong J, Shang H, Shi H, Pan P. Motor and extra-motor gray matter atrophy in amyotrophic lateral sclerosis: quantitative meta-analyses of voxel-based morphometry studies. Neurobiol Aging. 2015;36:3288-99.

32. Shen B, Gao Y, Zhang W, Lu L, Zhu J, Pan Y, et al. Resting state fMRl reveals increased subthalamic nucleus and sensorimotor cortex connectivity in patients with Parkinson's disease under medication. Front Aging Neurosci. 2017;9:74.

33. Wang WY, Yu JT, Liu Y, Yin RH, Wang HF, Wang J, et al. Voxel-based metaanalysis of grey matter changes in Alzheimer's disease. Transl Neurodegener. 2015;4:6

34. Li HJ, Hou XH, Liu HH, Yue CL, He Y, Zuo XN. Toward systems neuroscience in mild cognitive impairment and Alzheimer's disease: a meta-analysis of 75 fMRI studies. Hum Brain Mapp. 2015;36:1217-32.

35. Alegria AA, Radua J, Rubia K. Meta-analysis of fMRI studies of disruptive behavior disorders. Am J Psychiatry. 2016;173:1119-30.

36. Pan P, Zhu L, Yu T, Shi H, Zhang B, Qin R, et al. Aberrant spontaneous lowfrequency brain activity in amnestic mild cognitive impairment: a metaanalysis of resting-state fMRI studies. Ageing Res Rev. 2017;35:12-21. 
37. Petersen RC, Doody R, Kurz A, Mohs RC, Morris JC, Rabins PV, et al. Current concepts in mild cognitive impairment. Arch Neurol. 2001;58:1985-92.

38. Petersen RC, Smith GE, Waring SC, Ivnik RJ, Tangalos EG, Kokmen E. Mild cognitive impairment: clinical characterization and outcome. Arch Neurol. 1999;56:303-8

39. Winblad B, Palmer K, Kivipelto M, Jelic V, Fratiglioni L, Wahlund LO, et al. Mild cognitive impairment-beyond controversies, towards a consensus: report of the international working group on mild cognitive impairment. J Intern Med. 2004;256:240-6.

40. Petersen RC. Mild cognitive impairment as a diagnostic entity. J Intern Med. 2004:256:183-94

41. Albert MS, DeKosky ST, Dickson D, Dubois B, Feldman HH, Fox NC, et al. The diagnosis of mild cognitive impairment due to Alzheimer's disease: recommendations from the National Institute on Aging-Alzheimer's Association workgroups on diagnostic guidelines for Alzheimer's disease. Alzheimers Dement. 2011;7:270-9.

42. Stroup DF, Berlin JA, Morton SC, Olkin I, Williamson GD, Rennie D, et al. Meta-analysis of observational studies in epidemiology: a proposal for reporting. Meta-analysis of observational studies in epidemiology (MOOSE) group. JAMA. 2000;283:2008-12.

43. Li W, Chen Z, Wu M, Zhu H, Gu L, Zhao Y, et al. Characterization of brain blood flow and the amplitude of low-frequency fluctuations in major depressive disorder: a multimodal meta-analysis. J Affect Disord. 2016;210:303-11.

44. Radua J, Grau M, van den Heuvel OA, Thiebaut de Schotten M, Stein DJ, Canales-Rodriguez EJ, et al. Multimodal voxel-based meta-analysis of white matter abnormalities in obsessive-compulsive disorder. Neuropsychopharmacology. 2014;39:1547-57.

45. Sohn BK, Yi D, Seo EH, Choe YM, Kim JW, Kim SG, et al. Comparison of regional gray matter atrophy, white matter alteration, and glucose metabolism as a predictor of the conversion to Alzheimer's disease in mild cognitive impairment. J Korean Med Sci. 2015;30:779-87.

46. Jacobs HI, Van Boxtel MP, Jolles J, Verhey FR, Uylings HB. Parietal cortex matters in Alzheimer's disease: an overview of structural, functional and metabolic findings. Neurosci Biobehav Rev. 2012;36:297-309.

47. Cavanna AE, Trimble MR. The precuneus: a review of its functional anatomy and behavioural correlates. Brain. 2006:129:564-83.

48. Leech R, Sharp DJ. The role of the posterior cingulate cortex in cognition and disease. Brain. 2014;137:12-32.

49. Mak LE, Minuzzi L, MacQueen G, Hall G, Kennedy SH, Milev R. The default mode network in healthy individuals: a systematic review and meta-analysis. Brain Connectivity. 2017;7:25-33.

50. Fransson P, Marrelec $\mathrm{G}$. The precuneus/posterior cingulate cortex plays a pivotal role in the default mode network: evidence from a partial correlation network analysis. Neurolmage. 2008;42:1178-84.

51. Schacter DL, Addis DR, Hassabis D, Martin VC, Spreng RN, Szpunar KK. The future of memory: remembering, imagining, and the brain. Neuron. 2012;76:677-94.

52. Garces P, Angel Pineda-Pardo J, Canuet L, Aurtenetxe S, Lopez ME, Marcos $A$, et al. The default mode network is functionally and structurally disrupted in amnestic mild cognitive impairment - a bimodal MEG-DTI study. Neurolmage Clinical. 2014;6:214-21

53. Cha J, Jo HJ, Kim HJ, Seo SW, Kim HS, Yoon U, et al. Functional alteration patterns of default mode networks: comparisons of normal aging, amnestic mild cognitive impairment and Alzheimer's disease. Eur J Neurosci. 2013;37:1916-24.

54. Pievani M, Pini L, Ferrari C, Pizzini FB, Boscolo Galazzo I, Cobelli C, et al. Coordinate-based meta-analysis of the default mode and salience network for target identification in non-invasive brain stimulation of Alzheimer's disease and behavior variant frontotemporal dementia networks. J Alzheimers Dis. 2017; in press

55. Addis DR, Wong AT, Schacter DL. Remembering the past and imagining the future: common and distinct neural substrates during event construction and elaboration. Neuropsychologia. 2007;45:1363-77.

56. Johannsen P, Jakobsen J, Gjedde A. Statistical maps of cerebral blood flow deficits in Alzheimer's disease. Eur J Neurol. 2000;7:385-92.

57. Raichle ME, MacLeod AM, Snyder AZ, Powers WJ, Gusnard DA, Shulman GL. A default mode of brain function. Proc Natl Acad Sci U S A. 2001;98:676-82.

58. Jack CR Jr, Knopman DS, Jagust WJ, Shaw LM, Aisen PS, Weiner MW, et al. Hypothetical model of dynamic biomarkers of the Alzheimer's pathological cascade. Lancet Neurol. 2010;9:119-28.

59. Medina D, DeToledo-Morrell L, Urresta F, Gabrieli JD, Moseley M, Fleischman $D$, et al. White matter changes in mild cognitive impairment and AD: a diffusion tensor imaging study. Neurobiol Aging. 2006;27:663-72.
60. Toga AW, Thompson PM. Mapping brain asymmetry. Nat Rev Neurosci. 2003:4:37-48

61. Loewenstein DA, Barker WW, Chang JY, Apicella A, Yoshii F, Kothari P, et al. Predominant left hemisphere metabolic dysfunction in dementia. Arch Neurol. 1989;46:146-52.

62. Thompson PM, Mega MS, Woods RP, Zoumalan Cl, Lindshield CJ, Blanton $R E$, et al. Cortical change in Alzheimer's disease detected with a diseasespecific population-based brain atlas. Cereb Cortex. 2001;11:1-16.

63. Thompson PM, Hayashi KM, de Zubicaray G, Janke AL, Rose SE, Semple J, et al. Dynamics of gray matter loss in Alzheimer's disease. J Neurosci. 2003; 23:994-1005.

64. Singh V, Chertkow H, Lerch JP, Evans AC, Dorr AE, Kabani NJ. Spatial patterns of cortical thinning in mild cognitive impairment and Alzheimer's disease. Brain. 2006;129:2885-93.

65. Daianu M, Jahanshad N, Nir TM, Toga AW, Jack CR Jr, Weiner MW, et al. Breakdown of brain connectivity between normal aging and Alzheimer's disease: a structural k-core network analysis. Brain Connect. 2013;3:407-22.

66. Ferreira LK, Diniz BS, Forlenza OV, Busatto GF, Zanetti MV. Neurostructural predictors of Alzheimer's disease: a meta-analysis of VBM studies. Neurobiol Aging. 2011;32:1733-41.

67. Kim JH, Lee JW, Kim GH, Roh JH, Kim MJ, Seo SW, et al. Cortical asymmetries in normal, mild cognitive impairment, and Alzheimer's disease. Neurobiol Aging. 2012;33:1959-66.

68. Long X, Zhang L, Liao W, Jiang C, Qiu B. Distinct laterality alterations distinguish mild cognitive impairment and Alzheimer's disease from healthy aging: statistical parametric mapping with high resolution MRI. Hum Brain Mapp. 2013;34:3400-10.

69. Barnes J, Scahill RI, Schott JM, Frost C, Rossor MN, Fox NC. Does Alzheimer's disease affect hippocampal asymmetry? Evidence from a cross-sectional and longitudinal volumetric MRI study. Dement Geriatr Cogn Disord. 2005;19:338-44.

70. Eickhoff SB, Laird AR, Grefkes C, Wang LE, Zilles K, Fox PT. Coordinate-based activation likelihood estimation meta-analysis of neuroimaging data: a random-effects approach based on empirical estimates of spatial uncertainty. Hum Brain Mapp. 2009;30:2907-26.

71. Turkeltaub PE, Eickhoff SB, Laird AR, Fox M, Wiener M, Fox P. Minimizing within-experiment and within-group effects in activation likelihood estimation meta-analyses. Hum Brain Mapp. 2012;33:1-13.

72. Radua J, Mataix-Cols D. Meta-analytic methods for neuroimaging data explained. Biol Mood Anxiety Disord. 2012;2:6

73. Welton T, Kent D, Constantinescu CS, Auer DP, Dineen RA. Functionally relevant white matter degradation in multiple sclerosis: a tract-based spatial meta-analysis. Radiology. 2015;275:89-96.

74. Costafreda SG. Pooling FMRI data: meta-analysis, mega-analysis and multicenter studies. Front Neuroinform. 2009;3:33

75. Bastin C, Kerrouche N, Lekeu F, Adam S, Guillaume B, Lemaire C, et al. Controlled memory processes in questionable Alzheimer's disease: a view from neuroimaging research. J Alzheimers Dis. 2010;20:547-60.

\section{Ready to submit your research? Choose BMC and benefit from:}

- fast, convenient online submission

- thorough peer review by experienced researchers in your field

- rapid publication on acceptance

- support for research data, including large and complex data types

- gold Open Access which fosters wider collaboration and increased citations

- maximum visibility for your research: over $100 \mathrm{M}$ website views per year

At BMC, research is always in progress.

Learn more biomedcentral.com/submissions 